\title{
Iowa Enters the Space Age: James Van Allen, Earth's Radiation Belts, and Experiments to Disrupt Them
}

\author{
JAMES RODGER FLEMING
}

THE SPACE AGE or, more accurately, the satellite age officially began on October 4, 1957, with the dramatic and historic launch of Sputnik 1 by the Soviet Union. Space exploration, however, has deeper roots in early twentieth-century rocketry and remote sensing. Those roots can be traced to Iowa through the work of space scientist James Van Allen. Van Allen became internationally famous for discovering new features of Earth's magnetic field: the eponymous Van Allen Belts. Coverage of his work by the press and in a recent biography has been overwhelmingly positive. But he also earned the less well-known and dubious distinction of having eagerly participated in top secret military experiments to disrupt the magnetosphere using nuclear weapons.

A close examination of Iowa's entry into the space age through the early career of Van Allen sheds new light on his dis-

1. "James Van Allen," Faculty/Staff Vertical File, various dates, RG 01-15-03, University of Iowa Archives, University of Iowa Libraries, Iowa City; Abigail Foerstner, James Van Allen: The First Eight Billion Miles (Iowa City, 2007). Foerstner employs archival materials and personal interviews but discounts the nefarious nature of the nuclear tests, linking Van Allen's role only to the need to ban above ground nuclear testing.

The research for this article was funded in part by a State Historical Society of Iowa Research Grant.

THE ANNALS OF IOWA 70 (Fall 2011). (C) The State Historical Society of Iowa, 2011. 
covery and disruption of the near space environment for scientific and military purposes, a move he later regretted. This story is relevant today because nuclear explosions in space by the United States and the Soviet Union constituted some of the earliest attempts at geoengineering, or intentional human intervention in planetary scale processes. ${ }^{2}$ Exploring Van Allen's early career provides an opportunity to tell the story of the emergence of the space age as a gradual evolution of capabilities rather than its usual telling as a reaction to Sputnik. His story also calls attention to the scientific-military nexus at the heart of the early space program. The result, in turn, casts Van Allen in a new light.

EXPLORATION of space was really only a dream until the twentieth century, when some key technical advances made it more of a possibility, even likely. In the 1920s rocket pioneer Robert $\mathrm{H}$. Goddard developed functioning liquid-fueled rockets and used them for weather photography. At about the same time, miniaturized radio transmitters attached to instrumented sounding balloons, or radiosondes, were developed to collect weather data to altitudes of up to 10 miles. In 1935 Russian scientist Sergei Vernov launched balloon-borne Geiger counters to take cosmic ray readings at high altitudes and to map variations in Earth's magnetic field. A German V-2 rocket reached an altitude of 56 miles in 1942, high enough to be considered the edge of space. ${ }^{3}$ These applications are direct predecessors of Van Allen's later work with sounding rockets and satellites.

After World War II, Van Allen participated in launches of captured V-2 rockets outfitted with scientific instruments to measure cosmic radiation at extreme altitudes. He chaired the influential V-2 Panel, formally known as the Upper Atmosphere Rocket Research Panel.

2. James Rodger Fleming, Fixing the Sky: The Checkered History of Weather and Climate Control (New York, 2010).

3. V. A. Dergachev, "Scientific Activity of Academician Sergei Vernov in Apatity (Kola Peninsula) and Leningrad during the Years 1968-1982," Astrophysics and Space Science Transactions 7 (2011), 137-44, accessible at doi:10.5194/astra-7137-2011; Smithsonian National Air and Space Museum, "50 Years of the Space Age: 1940s: Vengeance Weapon 2: The V-2 Ballistic Missile," at www.nasm.si .edu/events/spaceage/vengeance.htm (accessed 6/15/2011). 


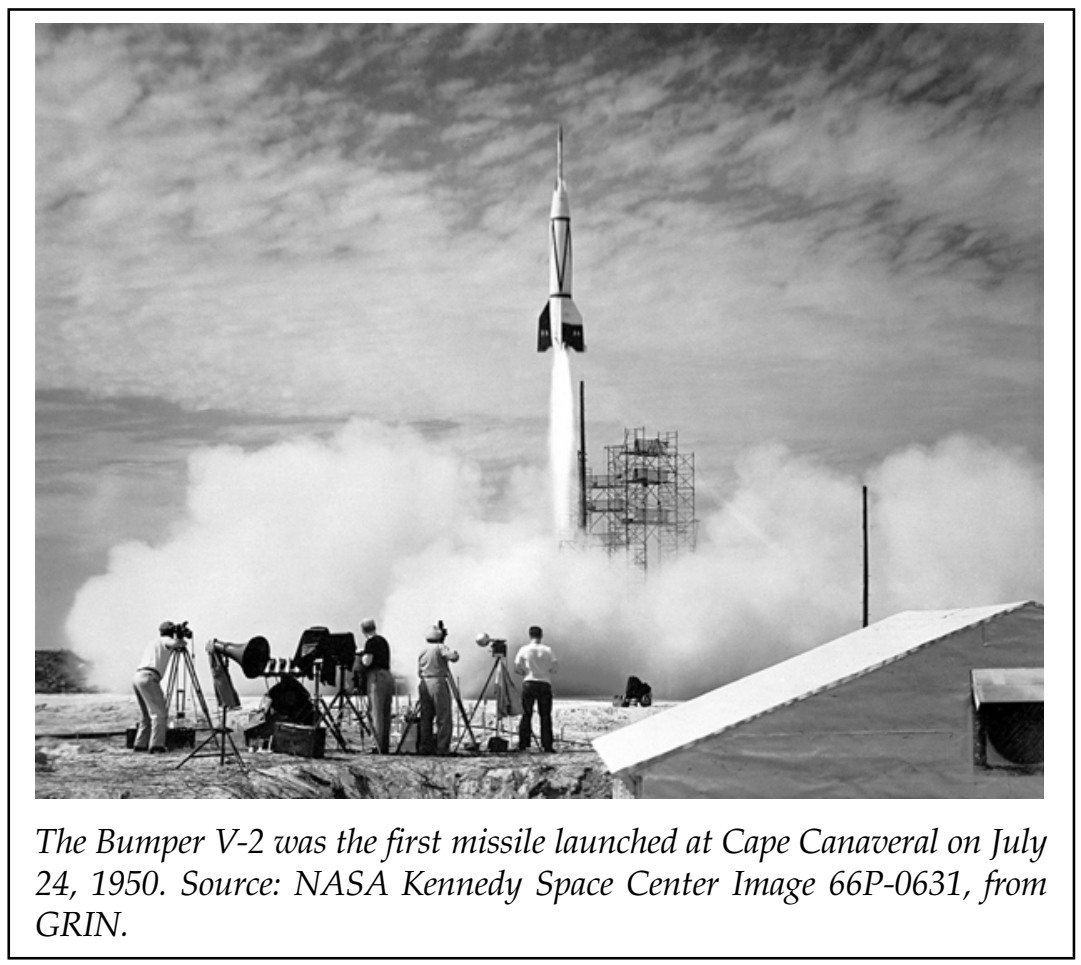

JAMES ALFRED VAN ALLEN (1914-2006) was born and raised in Mount Pleasant, Iowa, graduated at the top of his high school class, and attended Iowa Wesleyan College, where he studied physics, graduating magna cum laude in $1935 .{ }^{4}$ His mentor there, Thomas Poulter, introduced him to the study of terrestrial magnetism and instructed him in the use of instruments borrowed from the Carnegie Institution of Washington's Department of Terrestrial Magnetism (DTM). While still an undergraduate, Van Allen established a small magnetic observatory on campus, conducted a magnetic survey of Henry County, and provided his measurements to the DTM. He also helped set up stations to measure the luminous trails of meteors in the atmosphere and prepared scientific instruments for Professor Poulter,

4. The following biographical paragraphs are based on David DeVorkin, "Van Allen, James A.," Complete Dictionary of Scientific Biography, 26 vols. (Detroit, 2008), 25:118-26; and "James Van Allen," Faculty/Staff Vertical File, ca. 1958. 
who was senior scientist on the second Byrd Antarctic Expedition in 1933-1935. Van Allen's undergraduate education gave him a taste of authentic scientific fieldwork and provided him with a strong foundation for a long and successful career studying Earth magnetism.

Both of Van Allen's advanced degrees were in experimental physics, which remained his forte. In graduate school at the State University of Iowa, Van Allen grew single crystals of pure zinc and measured their mechanical properties, earning a master's degree in 1936. He remained at Iowa to study nuclear physics, measuring hydrogen and deuterium interaction crosssections for his Ph.D., which he earned in 1939. Here was a very bright Iowa boy, who had flourished in Iowa schools, now at the cutting edge of observation and experimentation, poised to enter the space age.

Van Allen accepted a postdoctoral fellowship at the DTM in Washington, D.C., where he continued to experiment on measuring and counting elementary particle interactions, especially nuclear gamma rays. There he was introduced to new ideas and opportunities involving the interaction between experimental nuclear physics and geophysics, especially those involving Earth's electrical and magnetic fields. Building on his undergraduate experience, and following the advice of geophysicist and DTM research associate Sydney Chapman, Van Allen compiled and analyzed observations of the fluctuations of Earth's magnetic field.

As the United States entered World War II, so too did Van Allen. He worked with the DTM and later with the Applied Physics Laboratory (APL), a new organization located in Silver Spring, Maryland, and managed by The Johns Hopkins University. There he designed radio-proximity fuses that detonated bombs, rockets, and shells when they were close to their targets. Making those sensitive devices, which contained vacuum tubes, rugged enough to withstand battle conditions was Van Allen's job, which he performed in conjunction with engineers from the Raytheon Corporation. Commissioned as a lieutenant in the U.S. Naval Reserve, Van Allen was assigned to the Pacific Fleet in November 1942 to test the new devices in the field and instruct gunnery teams in their use in combat. He received three 
combat stars and attained the rank of lieutenant commander by the end of the conflict. He later thought that his wartime experiences working with people and equipment under stressful and uncertain conditions helped prepare him for the intense pressures of the space race. Shooting electronic devices out of cannons was actually much harder than launching them on rockets.

After the war, married to Abigail Halsey and with a first child on the way, Van Allen returned to the APL, where he organized and supervised the High Altitude Research Group, a team tasked with designing instruments and experiments to fly on captured V-2 missiles. He also developed a new generation of small rocket research probes, later called Aerobees, which could be launched either from land or from ships. The army was launching the V-2s and Aerobees from White Sands, New Mexico, on its own schedule, so Van Allen's team had to move fast to have their instruments and devices - cosmic ray detectors, spectrographs, gas samplers, temperature monitors, flight data recorders and transmitters, and even parachute recovery systems - ready for launch. ${ }^{5}$ This hectic pace was also characteristic of the military-industrial nature of the later space age. Launching rockets from naval vessels gave Van Allen's team more control and more flexibility, since they could conduct high altitude geophysical research at various latitudes, including near the poles. One navy ship that launched Aerobee missiles for Van Allen in 1949 and 1950, the USS Norton Sound, would feature prominently later in the Argus atomic bomb tests in near space.

The groundwork for an important development was laid on April 5, 1950, when Sydney Chapman gave a lecture at the APL and that evening was the guest of honor at a dinner party at the home of James and Abigail Van Allen in Silver Spring, Maryland. According to legend, after dinner geophysicist Lloyd V. Berkner proposed and Chapman supported the idea of a third international polar year. This subsequently became the International Geophysical Year (IGY) of 1957-58, a coordinated effort, managed largely by Berkner and Chapman through the International Council of Scientific Unions, in which 67 nations conducted

5. James A. Van Allen, "Cosmic Ray Observations at High Altitudes by Means of Rockets," Sky and Telescope 7 (1948), 171-75. 
research at both poles, around the globe, and in outer space. ${ }^{6}$ The IGY provided opportunities for Van Allen to expand his research program using sounding rockets, while developing the new satellite program.

In 1951 Van Allen accepted the chairmanship of the State University of Iowa's physics department. Prior to moving to Iowa he completed a Guggenheim Fellowship at Brookhaven National Laboratories, where he studied the interrelations of high-energy physics and geophysics. He also took a research leave to work on fusion reactor design at Princeton University, a position that required that he obtain a top secret " $\mathrm{Q}$ " clearance, but nuclear fusion was not his main interest.

With modest support from the Office of Naval Research, the Atomic Energy Commission, and the U.S. Navy, Van Allen was able to maintain a field program to launch instrumented sounding rockets from high-altitude balloons - the so-called Rockoon program - by which he was able to take relatively inexpensive scientific measurements of cosmic ray intensity and the geomagnetic field at altitudes of 60 miles or more. Rockoons could be fired at will in all latitudes, anywhere the navy agreed to take him. From 1952 to 1957, Van Allen and his team traveled the world on naval vessels, using them as launch stations for rockoons. This was done for several hundred dollars per shot, compared with thousands or tens of thousands of dollars for an Aerobee or V-2 rocket launch.

Anticipation of the capabilities of a future Earth satellite ran high in the early 1950s. At a symposium on space travel held at New York's Hayden Planetarium in 1954, U.S. Weather Bureau research director Harry Wexler lectured on the possibilities of observing Earth's weather from a satellite vehicle both as a "storm patrol" and also as a potentially revolutionary new scientific tool with global capabilities. ${ }^{7}$ A year later the United States announced that it would launch a scientific Earth satellite during

6. Gregory A. Good, "Sydney Chapman: Dynamo behind the International Geophysical Year," in Globalizing Polar Science: Reconsidering the International Polar and Geophysical Years, ed. Roger D. Launius, James Rodger Fleming, and David H. DeVorkin (New York, 2010), 185-88; Allan A. Needell, "Lloyd Berkner and the International Geophysical Year Proposal in Context," ibid., 205-6.

7. James Rodger Fleming, "Polar and Global Meteorology in the Career of Harry Wexler, 1933-62," in Globalizing Polar Science, 233-35. 


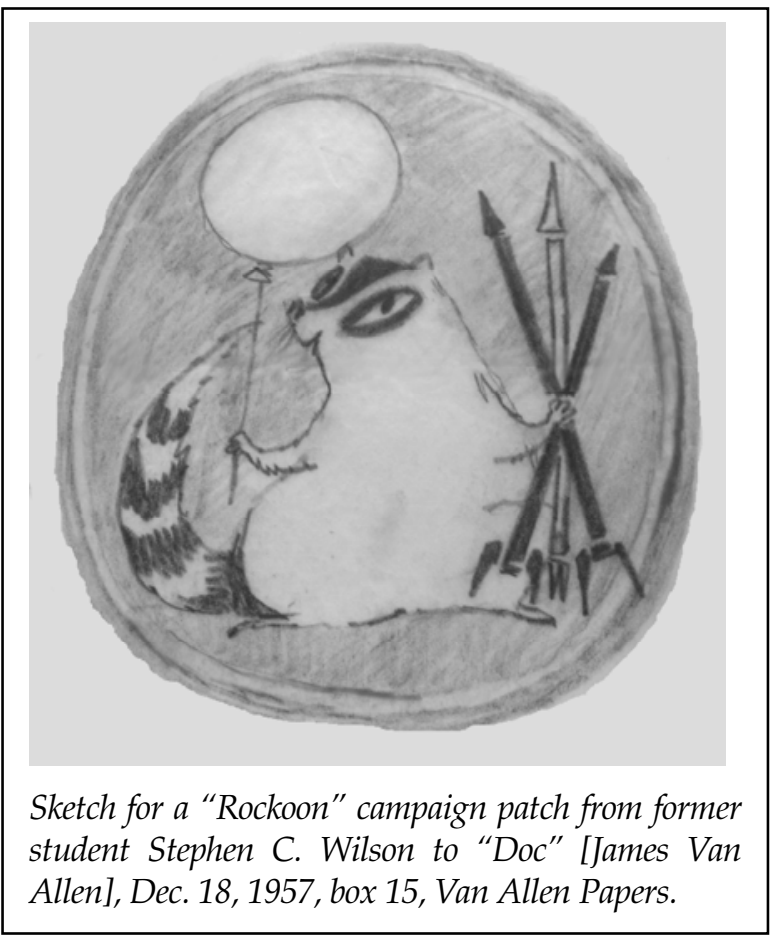

the upcoming IGY through its Vanguard program, a hybrid military-civilian effort spearheaded by the navy, supervised by the Department of Defense, and funded by the National Science Foundation. The satellite would use modified Viking and Aerobee sounding rockets. Excited by the opportunity, Van Allen and his graduate student George Ludwig prepared "A Proposal for Cosmic Ray Observations in Earth Satellites" for the National Academy of Sciences. Van Allen also edited a book on the scientific uses of Earth satellites. ${ }^{8}$ According to Van Allen, the early rocket and rockoon flights revealed the presence of "the [electrons] that produce aurorae" and inspired the instrumentation for the first U.S. satellites. ${ }^{9}$

8. James A. Van Allen to Joseph Kaplan, 9/28/1955, "A Proposal for Cosmic Ray Observations in Earth Satellites," Satellite Experiments file, folder 32.1, Archives of the National Academy of Sciences: IGY USNC; James A. Van Allen, ed., Scientific Uses of Earth Satellites (Ann Arbor, MI, 1956).

9. James A. Van Allen, "Early Days of Space Science," Journal of the British Interplanetary Society 41 (1988), 11-15. 
The launch of Sputnik 1 in October 1957, however, diverted the world's attention from scientific concerns and focused American perceptions on a "missile gap" and possible national security threats from space. The launch of Sputnik 2 the following month further fueled these fears, as did the spectacular failures of the U.S. Vanguard rocket program. The very first satellite launches garnered widespread attention and also resulted in important new scientific discoveries. Although Sputnik 1 carried no remote sensing instruments, its orbital decay provided information about the density and dangers of the near-space environment. The operation of its two radio transmitters also provided clues regarding the electron density of the ionosphere and indicated that the satellite's pressurized nitrogen compartment had not been punctured by micrometeorites. Sputnik 2 was primarily a biological experiment aimed at providing life support systems and telemetry for its doomed passenger, the dog Laika, but it also carried a cosmic ray experiment designed by Vernov. ${ }^{10}$ During the Sputnik launches Van Allen was "out of town and out of touch" on the USS Glacier en route to Antarctica, launching his small rockoons as part of the IGY's Operation Deep Freeze. ${ }^{11}$

IN RESPONSE to the Sputnik space spectaculars and the languishing Vanguard program, the U.S. Army Ballistic Missile Agency, with the help of the Jet Propulsion Laboratory, launched a four-stage modified Jupiter C military missile, designated Juno 1, on January 31, 1958. It carried the first U.S. satellite, Explorer 1 (satellite 1958 alpha), into orbit with an instrument package designed by Van Allen and hastily modified by George Ludwig to fit into the new satellite. An identical satellite, Explorer 2 (1958 beta), failed to reach orbit on March 5, but Explorer 3 (1958 gamma), with improved instruments, successfully orbited the Earth on March 26.

10. M. I. Panasyuk, “Cosmic Ray Physics in Space: The Role of Sergey Vernov's Scientific School," Astrophysics and Space Science Transactions 7 (2011), 151-56, accessible at doi:10.5194/astra-7-151-2011.

11. David DeVorkin and Allan Needell, “Oral History Interview with James A. Van Allen" (Washington, DC: Smithsonian National Air and Space Museum Oral History Program, 1981), 253; Dian Olson Belanger, Deep Freeze: The United States, the International Geophysical Year, and the Origins of Antarctica's Age of Science (Boulder, CO, 2006). 


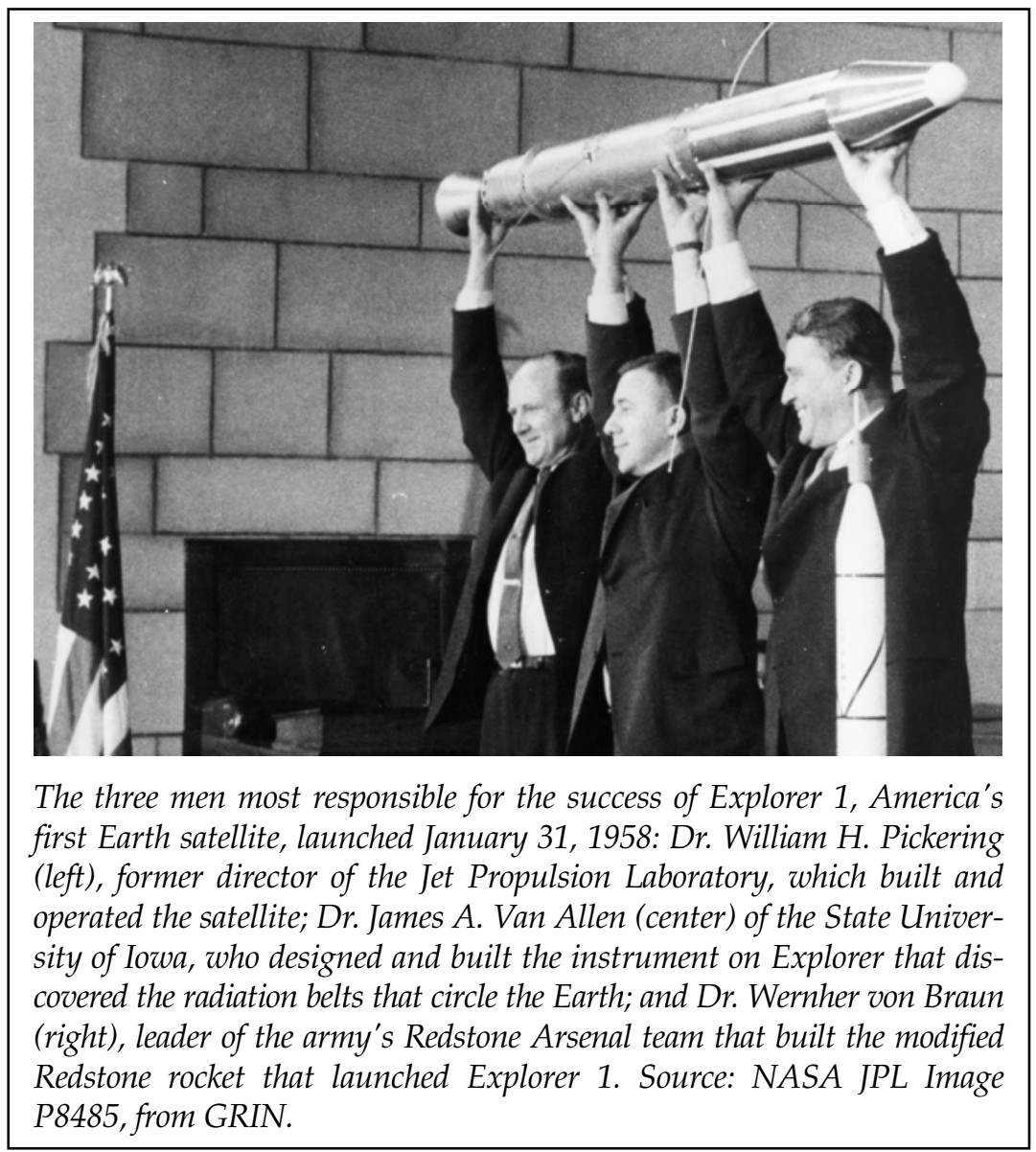

Explorer 1's launch date was a very happy day for Van Allen - so happy in fact that in a photograph he and his colleagues are shown with the satellite hoisted above their heads in a triumphant stance. He later recalled,

It was a kind of a public media event as it turned out, because we were sort of helping rescue the honor of the United States.... We were like the heroes who raised the flag over Iwo Jima, sort of temporary heroes, rescuing the honor of the United States in this great cold war with Russia, by having had a successful satellite. This was especially because of the really humiliating failures of 
the Vanguard program, which had been our bid for national recognition and achievement. ${ }^{12}$

Early results retrieved from the satellites were inconclusive but eventually turned out to be scientifically spectacular. Explorer 1 sent back intermittent data where cosmic ray intensity information was expected. Van Allen and his team thought the gaps were due to a machine malfunction.

Well, first of all, the Explorer 1 data was very meager. . . . There were just little bits and pieces of data, and it was terribly hard to tell what was going on. . . . So it accumulated pretty slowly, and you couldn't get the picture. The only picture we got was that there's something funny going on here. We considered the apparatus was malfunctioning in some very puzzling way, but we were reluctant to believe that because . . . we had a very conservative design. $^{13}$

The instruments on Explorer 3 returned about 100 times more information than those on Explorer 1. This is because they were connected to a magnetic tape recorder that recorded the data from an entire orbit, then, on command, played it back to a receiving station. By the first week of April 1958, Van Allen and his group - George Ludwig, Carl Mcllwain, and Ernie Ray realized that the instruments on both satellites were functioning properly and that they had encountered some "real physical phenomenon." ${ }^{14}$

On May 1, 1958, at the National Academy of Science, Van Allen announced that Geiger-Müller counters aboard Explorers 1 and 3 had been swamped by high radiation levels at certain points in their orbits, indicating that powerful radiation belts, later known as the Van Allen Belts, surround Earth in a donutshaped torus. This was a stunning new discovery, the first of the space age. Van Allen recounted the discovery of "great bands of corpuscular radiation," belts of high-energy particles a thousand

12. DeVorkin and Needell, "Oral History Interview with James A. Van Allen," 266.

13. Ibid.

14. Ibid., 272; J. A. Van Allen, G. H. Ludwig, E. C. Ray, and C. E. Mcllwain, "Some Preliminary Reports of Experiments in Satellites 1958 Alpha and Gamma," IGY Satellite Report Series no. 3 (1958), 73-92; James A. Van Allen, "Radiation Belts around the Earth," Scientific American 200 (March 1959), 39-47. 
times more intense than cosmic rays, that were temporarily trapped in Earth's magnetic field. He likened the phenomena to "bees in a hive." ${ }^{15}$ James Van Allen of Mount Pleasant and Iowa City was now an internationally famous man, snagging a personal invitation to dine with the Eisenhowers at the White House on February 4, 1958, and reaching the cover of Time magazine twice: once all by himself in 1958 and once in a group of scientists named "men of the year" in $1961 .{ }^{16}$

ON THE VERY SAME DAY that Van Allen announced his discovery of Earth's radiation belts to the world, he agreed to join Project Argus, a top secret military test aimed at detonating atomic bombs in space to generate an artificial radiation belt, disrupt the near space environment, and possibly intercept enemy missiles. According to Van Allen, "We had been selected or entrusted with doing the primary satellite experiment for observation of the Argus tests. That all happened in the first few days of May, '58. That was all settled, in fact, already in late April. We had a go-ahead on the same day I gave the National Academy lecture on the 1st of May." ${ }^{17}$ As was the case with Explorer 1, Van Allen was proud to be working for the U.S. government in its attempts to outdo the Soviet Union in space.

On April 5, 1958, with the Geiger counter returns coming in from Explorers 1 and 3, Van Allen's assistant Ernie Ray had written ominously on the blackboard in the Iowa physics department, "Space is Radioactive." Now the military wanted to make space even more radioactive by nuclear and, later, thermonuclear detonations that in times of war could disrupt enemy radio communications from half a world away and damage or destroy enemy satellites and intercontinental ballistic missiles. Van Allen eagerly participated in A-bomb and even larger $\mathrm{H}$ bomb detonations in space in Project Argus and Project Starfish Prime with no misgivings. "I certainly never resisted the oppor-

15. J. A. Van Allen, "A Great New Field of Endeavor: The Investigation of Outer Space," typescript, box 406, Van Allen Papers.

16. Time Magazine, 5/4/1958, 1/2/1961.

17. DeVorkin and Needell, "Oral History Interview with James A. Van Allen," 277. 
tunity," he admitted. "I was keen and eager to do it [Project Argus]. I didn't have any doubt in my own mind that I wished to do it, so it was an almost immediate agreement. . . . I didn't really know much about the bomb business. I thought, if they were going to make a test, [space] was a good place to make one, as far as absence of fallout goes and adverse effects." ${ }^{18}$ Such were the early links between early space science and planetary scale engineering - or "geoengineering."

On May 10, 1958, Van Allen attended a meeting on the Argus Project in Pasadena, California, with high-level representatives from the Jet Propulsion Laboratory, the Army Ballistic Missile Agency, and the Naval Research Lab. There, according to his meeting notes, it was "Agreed: SUI will coordinate payload assembly!" for a new satellite, Explorer 4, to be launched into orbit just prior to the bomb tests. The university was awarded a contract for $\$ 123,000$ for its participation. ${ }^{19}$

Explorer 4 was announced as part of a peaceful IGY satellite program, but the design and construction of the instrument package was top secret, and it was used for military purposes. Working under intense time pressure, Van Allen and his team assembled the devices in the university's basement physics labs, with the rationale that it was a perfect cover, since no one, including Soviet spies, would expect to find classified work being done at a midwestern state university, and a casual visitor to the lab would see only a mass of tangled wires and vacuum tubes. However, the Atomic Energy Commission and the Department of Defense monitored every shipment and every movement of supplies and equipment. Van Allen chafed at the paperwork but was glad to play a central role in the project. He did not reveal the project's military objectives to his team members, just that they were making a new set of instruments, the fourth installment in the series. ${ }^{20}$

18. Ibid., 281.

19. James Van Allen, handwritten meeting notes on Project Argus and contract for Design and Development of Radiation Detection Devices, box 89, Van Allen Papers. SUI refers to the State University of Iowa, now known as the University of Iowa.

20. J. A. Van Allen, "The Argus Experiments," typescript, box 406, Van Allen Papers; James A. Van Allen, Carl McIlwain, and George Ludwig, "Satellite Observations of Electrons Artificially Injected into the Geomagnetic Field," Journal of Geophysical Research 64 (1959), 877-91. 


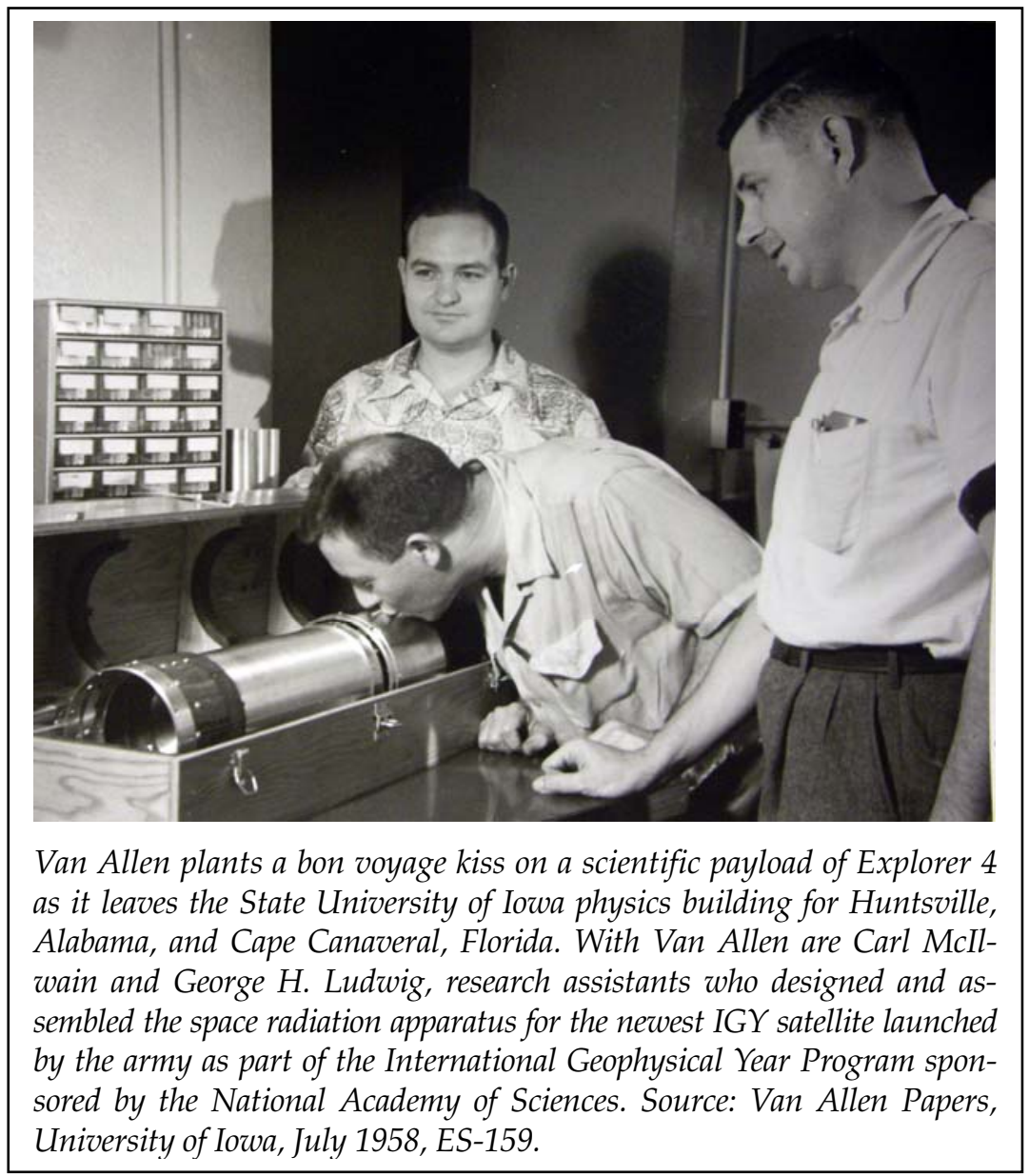

High-altitude nuclear testing was well under way in 1958 in the Hardtack I test series. In April the U.S. military detonated a small atomic bomb, "Yucca," 16 miles above Enewetak Atoll in the Pacific Ocean as a test of its antiballistic missile defense program. In July and August, the U.S. military tested two much larger hydrogen bombs high above Johnston Island in the Pacific Ocean. "Teak," a 3.8-megaton blast set off at an altitude of 46 miles, was visible across the Pacific. The shot triggered an artificial aurora that filled the sky with brilliant colors 2,000 miles away in Samoa, and, because it severely disrupted the ionosphere, blacked out radio communications as far away as 
Australia and New Zealand for as long as six hours. This was precisely what the military had hoped the test would do. The fireball was clearly visible from Hawaii, where air traffic was grounded for several hours. One air force officer watching the display fantasized that this is what a nuclear war might look like. After a radio silence lasting eight hours, and worried that the test shot may have knocked out the base, the Pentagon sent a message to Johnston Island asking, "Are you still there?"21 Less than a fortnight later, an equally powerful bomb, "Orange," was detonated in the stratosphere at an altitude of 27 miles, too low to generate an appreciable aurora or black out radio communications, but perfect for tracing fallout patterns as they circled the globe. Although the military had requested additional shots, in mid-August President Eisenhower announced a one-year moratorium on nuclear testing to take effect on October 31, 1958. ${ }^{22}$ Because of the new deadline, the Argus Project went into high gear.

The Argus space shots consisted of three atomic bombs, each of 1.7-kiloton yield, detonated at altitudes of 120, 150, and 288 miles above the South Atlantic Ocean on August 27, August 30, and September 6, 1958. Explorer 4, although publicly announced as part of the IGY, had been purpose built for these shots. It carried four shielded Geiger counters, each with different, yet all very high counting rates, since astronomical numbers of bomb particles were expected and were indeed encountered. The goal, as reported by Van Allen a year later, was to probe the natural Van Allen belts by giving them a shock to see if artificial radiation belts could be created and monitored. But something much more pernicious was afoot.

The idea of detonating bombs in near space had been proposed in 1957 by Nicholas Constantine Christofilos, a physicist at Lawrence Berkeley Lab. ${ }^{23}$ His hypothesis, which was pursued by the Department of Defense's Advanced Research Projects Agency (ARPA) and tested in Project Argus and other nuclear

21. Defense's Nuclear Agency 1947-1997 (Washington, DC, 2002), 140, at www.dtra .mil/documents/aboutdtra/DefensesNuclearAgency.pdf (accessed 6/15/2011).

22. Ibid., 141-43.

23. Alan A. Needell, "Christofilos, Nicholas C.," Complete Dictionary of Scientific Biography, 17:166-68. 
shots, held that the debris from a nuclear explosion, mainly highly energetic electrons, would be contained within lines of force in Earth's magnetic field and would travel almost instantly as a giant current spanning up to half a hemisphere. ${ }^{24}$ Thus, if a detonation occurred above a point in the South Atlantic, immense currents would flow along the magnetic lines to a point far to the north, such as Greenland, where they would severely disrupt radio communications; a shot in the Indian Ocean might, then, generate a huge electromagnetic pulse (EMP) over Moscow. In addition to providing a planetary "energy ray," nuclear shots in space, Christofilos thought, might also disrupt military communications, destroy satellites and the electronic guidance systems of enemy ICBMs, and possibly kill any military cosmonauts participating in an attack launched from space. ${ }^{25}$

In the event of a nuclear attack, Christofilos proposed launching thousands of nukes to make a space shield. So Project Argus was initiated by the ARPA and the Air Force Special Weapons Program to test the "Christofilos effect" and to see if nuclear tests in space could be detected by remote sensing. Because of the need for secrecy (and deniability) and the accompanying need for a remote location, and due to geomagnetic considerations as well, a nine-vessel naval convoy conducted the tests in the South Atlantic Ocean. The guided missile ship USS Norton Sound, a converted World War II-era seaplane tender that had launched Aerobee missiles for Van Allen over the years, was designated to fire the three-stage, solid fuel, nucleartipped missiles. The aircraft carrier USS Tarawa, equipped with radar and antisubmarine reconnaissance planes, tracked the launches and searched for Russian submarines in the area.

Explorer 4 (satellite 1958 delta), launched on July 26, 1958, was in orbit for both the Teak and Orange detonations and made multiple passes through the artificially induced radiation belts generated by the Argus shots. High-altitude sounding rockets were also used to monitor the Argus blasts. The U.S. Air Force

24. N. C. Christofilos, "The Argus Experiment," Journal of Geophysical Research 64 (1959), 869.

25. Similar but smaller-scale projects are discussed in Christopher J. Bright, Continental Defense in the Eisenhower Era: Nuclear Antiaircraft Arms and the Cold War (New York, 2010). 


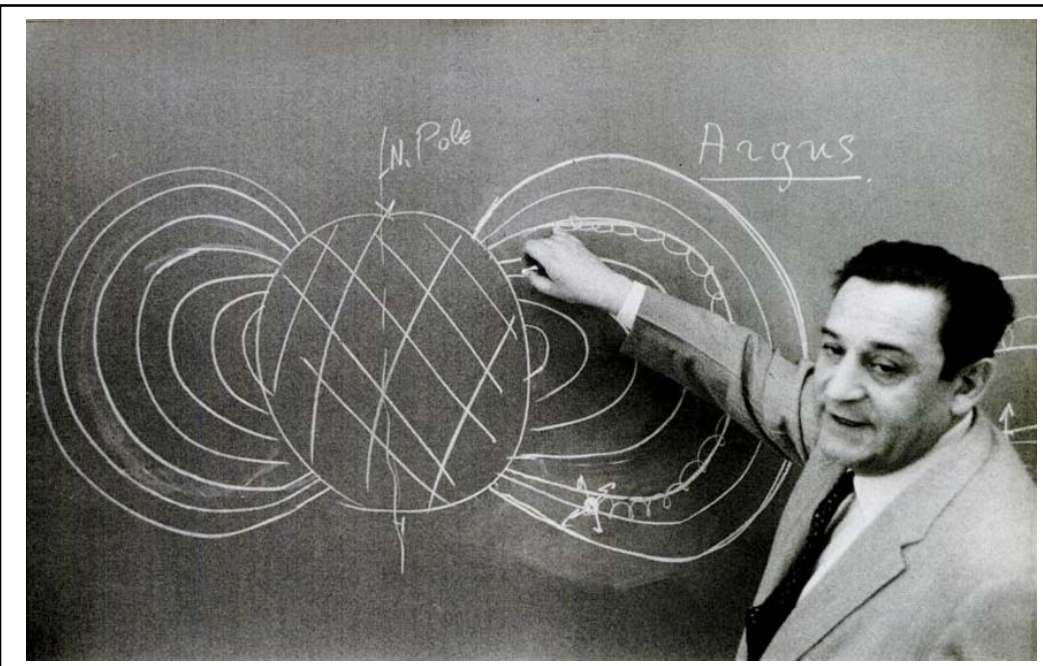

Original Caption: "Explaining Argus: Christofilos shows how magnetic field encompasses the Earth (center). When nuclear bomb is detonated (symbol at lower right) some of its radiation is trapped and travels along lines of magnetic force to point at opposite end of the line. Then it spreads around the Earth in a thin shell of electrons." Source: William Trombley, "Triumph in Space for a 'Crazy Greek': Theory of Boston-born maverick scientist led to sensational Project Argus," Life Magazine 46 (3/30/1959).

Special Weapons Center at Kirtland Air Force Base, New Mexico, supervised the launch of 19 solid fuel rockets sent to altitudes of 480 miles to measure decay products of the bombs. This was called Project Jason. ${ }^{26}$

What were the lessons of Argus? The project demonstrated that, with interservice and scientific cooperation, a top secret nuclear test series could be conducted surreptitiously and in short order; just ten months elapsed from concept to execution. It was also the first launch of a nuclear-tipped missile from a ship and the only nuclear operation ever conducted in the Atlantic Ocean. The bombs generated temporary artificial radiation belts that were too weak to verify Christofilos's theory about interfering

26. L. Allen Jr., J. L. Beavers II, W. A. Whitaker, J. A. Welch Jr., and R. B. Walton, "Project Jason Measurement of Trapped Electrons from a Nuclear Device by Sounding Rockets," typescript report, U.S. Air Force Special Weapons Center, Kirtland Air Force Base, New Mexico, n.d., copy in box 200, Van Allen Papers. 
with communications and destroying incoming enemy missiles, but were promising enough to fuel speculation that more bombs or more powerful bombs in space could still do the job. ${ }^{27}$

The Argus shots were supposed to remain classified, but their status quickly changed when the New York Times broke the story on March 20,1959, with no less than seven articles in that day's edition. The front-page story focused on weapons research and the attempt to halt enemy missiles; an editorial on page 30 said that the participants had called Argus "the greatest scientific experiment of all time" and speculated that it might "lead to peace among the nations of the world"; but the Pentagon's press conference on Project Argus quickly put the lie to these claims when Deputy Secretary of Defense Donald Quarles was unable to answer the reporters' questions, especially when asked how the tests fit with the peaceful purposes of the IGY. Quarles replied, "I would like to make it clear that we do not represent this to be solely a scientific experiment any more than the first reactor that went critical near Chicago was solely a scientific experiment." A reporter then commented, "Sir, we have been here more than an hour and we still don't know what your basic purposes were in the [experiment]."

Van Allen, although he was enjoined not to discuss the military implications of Argus, was also quoted in the Times that day in response to a hypothetical question. "If a host of neutrons could be released at great altitude, could they split the nuclei of a missile warhead and detonate it?" a reporter asked. "Yes - if there were enough of them," the University of Iowa scientist replied. ${ }^{29}$ According to an official review of the episode, "The public controversy over Argus ... had less to do with testing per se than with the nuclear agencies' deliberate failure to keep Congress informed of their plans. The implication, disquieting in light of the ongoing test ban negotiations, was that tests conducted in outer space could go entirely undetected." ${ }^{30}$

27. Herbert F. York, Making Weapons, Talking Peace: A Physicist's Odyssey from Hiroshima to Geneva (New York, 1987), 149; Defense's Nuclear Agency 1947-1997, 146.

28. New York Times, 3/20/1959.

29. Ibid.

30. Defense's Nuclear Agency 1947-1997, 154. 
Van Allen put a neutral spin on the Argus shots by reporting on their experimental rather than military nature. He emphasized that they allowed Earth's magnetic field to be rung like a bell, to be plotted experimentally for the first time, and that a known quantity and intensity of electrons injected by the blasts would help scientists understand natural processes, including radio transmission. The hybrid civilian/military nature of Explorer 4 is clearly seen in Van Allen's final report of the radiation measurements, in which he credits assistance by the "US/IGY Project 32.1 of the National Academy of Sciences and the National Science Foundation; by the U.S. Army Ordnance Department; and by the Office of Naval Research and the Atomic Energy Commission." ${ }^{\prime 1}$

Argus demonstrated that a state university in the American heartland and an IGY satellite planned for peaceful exploration could be co-opted for the cold war. Although most of the direct monitoring of the explosions was conducted by the military from the surface and by sounding rockets, the four hardened Geiger counters on Explorer 4 were purpose built by Van Allen and his team out in the open in the basement of the Iowa physics department. The Jet Propulsion Laboratory (JPL), which top administrators wished to shield from weapons-related work, eagerly accepted contracts from the Army Ballistic Missile Agency for studies on the survivability of missiles reentering Earth's atmosphere. The JPL also built the Explorer series of satellites, initially planned for the peaceful and scientific study of the planet, but used as well to monitor top secret nuclear tests in space. ${ }^{32}$ The tests reinforced Van Allen's inestimable value to the, by then, highly militarized space program. His top-level security clearance, held since World War II, was indeed well placed, allowing him to mix freely in civilian and top secret circles.

31. J. A. Van Allen, C. E. Mcllwain, and G. H. Ludwig, "Radiation Observations with Satellite 1958 Epsilon," Department of Physics, State University of Iowa, n.d., copy in box 405, Van Allen Papers.

32. Defense's Nuclear Agency 1947-1997, 143-46; Erik M. Conway, "From Rockets to Spacecraft: Making JPL a Place for Planetary Science," Engineering E Science 4 (2007), 2-10. 
ON AUGUST 31, 1961, the Soviet Union announced that it was ending the moratorium on atmospheric nuclear testing. It detonated an 11-kiloton device in the stratosphere on September 6 and a massive 50-megaton weapon, the Tsar Bomba, on October 30 at an altitude of only 2.5 miles over the Novaya Zemlya test range. The Soviets went on to detonate three more relatively small space-bombs that year and three larger devices in 1962, between October 22 and November 1 - the height of the Cuban Missile Crisis. The EMP from one of the tests over Kazakhstan short-circuited electrical systems and destroyed telephone lines, in one case igniting a fire that burned down a power plant.

On July 8, 1962, almost four years after Project Argus, a 1.4megaton hydrogen bomb designated Starfish Prime was carried aloft by a Thor missile and detonated 240 miles above Johnston Island. The blast, nearly a thousand times more powerful than the Argus explosions, generated an artificial aurora in low latitudes that scientists referred to as the "Aurora tropicalis." In Honolulu, 700 miles away, the explosions were front-page news. "N-Blast Tonight May Be Dazzling: Good View Likely," the Honolulu Advertiser proclaimed. Hotels held what they called "Rainbow Bomb Parties" on rooftops and verandas. When the bomb burst, people told of blackouts and strange electrical malfunctions, like garage doors opening and closing on their own. But the big show was in the sky. ${ }^{33}$ The blast disrupted the natural Van Allen belts, knocked out radio communications across the Pacific, destroyed several communication satellites (notably Telstar, whose solar cells were damaged), and generated a massive EMP that set off burglar alarms and air-raid sirens and damaged about 300 streetlights in Hawaii. Earth currents and magnetic field disturbances propagated throughout the world. Scientists later estimated that if a bomb the size of Starfish Prime were to be detonated over the continental United States, where Earth's magnetic field is stronger, EMP would be about 2.4 times stronger and would burn out circuits across the entire nation. ${ }^{34}$

33. Robert Krulwich, "A Very Scary Light Show: Exploding H-Bombs in Space," National Public Radio, 2010, www.npr.org/templates/story/story.php? storyId=128170775 (accessed 6/15/2011).

34. J. Robertson, "U.S. Seeks Answers to A-blast Oddity," Electronic News 30 (Oct. 1967), 22. 
A New Yorker cartoon depicted a serious-looking technocrat questioning a colleague in a high-tech laboratory setting: "But how do you know destroying the inner Van Allen belt will create havoc until you try it?" ${ }^{\prime 35}$ British radio astronomer Bernard Lovell, along with the International Astronomical Union, issued a formal protest: "No government has the right to change the environment in any significant way without prior international study and agreement."

Although the effects of the 1958 Argus tests were short-lived, the Starfish Prime shot of 1962 created a new radiation belt that persisted for ten years, problematizing further study of the natural radiation belts. Nevertheless, during this period Van Allen and his Iowa team designed and built Explorer 15 (1962) and the Injun series of solar-powered satellites (1961-1974) to study the artificial radiation belt. Van Allen admitted that because of the longer-than-expected persistence of the artificial belts, experiments to solve "some nice little scientific questions" about the natural inner belt will be "hopelessly fouled up for some time." He had predicted that the effects would last a year. When asked about his inaccurate forecast, Van Allen stated, "It's the difference between intuitive expectations and actual observations." With U.S. astronauts and Soviet cosmonauts in orbit at the time, he also believed that the Starfish Prime shot "had increased the potential danger for manned space flights." ${ }^{37}$

The upper atmosphere bomb blasts by the Soviets and the Americans were failed attempts to harness Earth's natural processes for strategic purposes. A military report on Starfish Prime, declassified in 1989 (a full 27 years after it was written), acknowledges this fact within the first three pages: "As an aid to penetration for incoming missiles by disrupting enemy anti-missile radars, Starfish Prime was not as effective as anticipated. Deto-

35. New Yorker, 5/26/1962, 31.

36. Dudley Saward, Bernard Lovell: A Biography (London, 1984), 243.

37. James A. Van Allen, "The Starfish Test," Nuclear Information 5 (Jan. 1963), 112; James A. Van Allen, L. A. Frank, and B. J. O’Brien, "Satellite Observations of the Artificial Radiation Belt of July 1962," Journal of Geophysical Research 68 (1963), 619-627; "High-Belt Radiation Fouls Experiments," newspaper clipping, 3/16/1963, Iowa Press Clippings Bureau, Van Allen Papers; J. Flansburg, "No Ivory Tower for Iowa's Van Allen," Des Moines Morning Register, undated (1965), ibid. 
nation degradation of communications and radar surveillance capabilities were found to be appreciably less than expected. ${ }^{\prime 38}$ According to the report (from which many pages and paragraphs are redacted), Starfish Prime had the following major "scientific" objectives:

1. Evaluation of missile kill mechanisms produced by a highaltitude nuclear detonation.

2. Evaluation of the effects of a high-altitude nuclear detonation on electromagnetic surveillance capability.

3. Evaluation of the effects of a high-altitude nuclear detonation on long-range communications.

4. Investigation of the basic characteristics of a high-altitude nuclear detonation and the physical basis of the effects.

5. Evaluation of high-altitude nuclear detonation weapon diagnostic techniques.

6. Evaluation of high-altitude nuclear detonation detection systems.

The Christofilos effect, although still of interest, was not mentioned in the redacted report, but a diagram indicating that space blasts could be used for offensive purposes was missed by the censors. The unredacted figure shows the use of a "precursor shot" at about 250 miles altitude to knock out the enemy's anti-ICBM radars - this to be followed by an ICBM attack.

AT THE START of his career James Van Allen proved that he was a leading experimentalist with interests in both radiation physics and electrical and magnetic geophysics. He helped develop the proximity fuse, a device that ranks, with radar and the atomic bomb, among the top three inventions of World War II. With a Ph.D. in physics, naval reserve officer status, and a life-long security clearance, Van Allen had ready access to early $\mathrm{V}-2$ missiles and other sounding rockets and rockoons of his own design. He was present at the genesis of the IGY, or at least host of the dinner at which it was hatched. When the space age formally began, Van Allen had the first instrument flying on the first U.S. satellite. It was a Geiger counter seeking to measure "cosmic rays" - or at least that was the cover story, since elec-

38. Francis Narin, comp., "A 'Quick Look' at the Technical Results of Starfish Prime" (Washington, DC, 1962; declassified 1989). 
tromagnetic theory had long predicted basic features of Earth's magnetosphere, and Christofilos was certainly not the only scientist to expect that clouds of charged particles might be found there.

Van Allen was a space scientist, a mid-twentieth-century example of what we might call an "Earth systems scientist." He knew that Earth processes work together and influence the whole planet.

The substance of space science is not a well-defined scientific discipline. Rather it is a loose federation of the traditionally defined and somewhat overlapping disciplines of atmospheric and ionospheric physics and chemistry, magnetospheric physics, geophysics, geology, oceanography, planetary magnetism, solar astronomy, radio astronomy, planetary astronomy, stellar and galactic astronomy, and the physics of the interplanetary medium, the interstellar medium, and other plasma physical systems. Certain aspects of biology and medicine are also included. ${ }^{39}$

Nevertheless, by participating in a project to detonate bombs in outer space aimed at disrupting and militarizing the magnetosphere, he was behaving quintessentially as a product of the mid-twentieth-century cold war. His actions, admittedly miscalculations, rendered the scientific study of a newly discovered planetary feature difficult if not impossible for over a decade.

Van Allen distrusted the Soviets and regretted their reaching space in advance of the United States. He also realized that his notable discovery of the radiation belts was fortuitous and could have been made by the Russians had they been faster in interpreting their own data. He knew that Sputnik 2 carried a Geiger counter with the ability to transmit evidence of cosmic radiation in the magnetosphere back to Earth, and his Soviet counterpart Sergei Vernov could have scooped him in the discovery if his equipment had worked properly.

When Van Allen visited the Soviet Union in the summer of 1959, he learned, firsthand, that scientific cooperation and information exchange between countries was not entirely free flowing, yet the Russian scientists were worthy of grudging respect. He once told a reporter, "I'm not fond of the Soviet way

39. Van Allen, "Early Days of Space Science," 11-15. 
of life. But there is a very strong journalistic tendency to say that the Russians won't tell us anything. It is part of our political bias. We must give the devil his due." ${ }^{40}$ After his return from the Soviet Union, government agents, most likely from the CIA, debriefed him. They asked him to describe in detail any recent significant developments in cosmic ray research and to note any incidents in which the Soviets appeared to be evasive or secretive about any aspect of their work. His responses were vague but not misleading or inaccurate.

Van Allen had learned how to play the game: there were certain things better not to be discussed. Many of Van Allen's associates from his time in the military were now senior officers, and he realized that his ability to fly his experiments in space was a byproduct of military developments, combined with good luck, hard work under crushing deadlines, and a dose of gamesmanship: "By virtue of the Explorers I and III and then the IV success, our little group [at Iowa] had a lot of clout in the system. In other words, almost anything we judged was reasonable to do, we had a very good chance of doing."

James Van Allen still holds a deservedly solid reputation as a good Iowan, family man, and space scientist, but his halo now has a decidedly nuclear glow. He was uniquely poised as a scientist to experiment on the whole Earth in an age when everything was possible, even urgent, given the state of the cold war. Because of him Iowa joined the space age. He prepared scientifically in the 1930s and '40s and recorded many significant accomplishments in high-altitude and near space research before 1957. His was not just a knee-jerk reaction to Sputnik, but a lifelong engagement with space.

For several years, from 1958 to 1962, Van Allen was a geoengineer. He discovered and participated in the disruption of the magnetosphere, a major planetary feature. He wrote about the science of it all, but he eagerly participated in the military aspects as well. After projects Argus and Starfish Prime were

40. G. Sperling Jr., "Birth of IGY: Radiation Finds Studied," typescript, Van Allen biographical file, University of Iowa Archives; this article later appeared in the Christian Science Monitor, 2/2/1959.

41. DeVorkin and Needell, "Oral History Interview with James A. Van Allen," 294. 
over, he stated, "[Science] is subjective. It's done by humans. The outcome is objective because it must withstand the test from all the people of the world." ${ }^{42}$ Unfortunately, his experiments with bombs in space, like many cold war-era interventions, raise troubling questions about his legacy.

I know of no more dramatic historical example of the discovery of a new phenomenon by a scientist who immediately agreed to cooperate with the military in an act aimed at disrupting it. Of course intervention is part of scientific practice, but the disruption of the magnetosphere constituted a purposeful and quite reckless intervention in a hitherto unknown and poorly understood global feature; that is, it constituted what we now call geoengineering. Astronomer Bernard Lovell accused the military scientists of taking a series of "huge gambles" with the planet: "The Earth is so minute on the cosmic scale and its environment is controlled by the delicate balance of such great natural forces that one must view with dismay a potential interference with these processes before they are investigated by the delicate tools of the true scientist."

Today, climate engineers wishing to cool the planet several degrees are also proposing to tinker with its geophysical systems. Their vague ideas include injecting sulfate aerosols or high-tech nanoparticles into Earth's stratosphere or adding iron to the oceans to generate massive algal blooms to sequester carbon dioxide - this, with little or no idea of the consequences. Thus, in Baconian terms, a modicum of understanding should immediately be leveraged, some geoengineers believe, to gain power over and control of nature for "useful" purposes, even if this involves disrupting the phenomenon. ${ }^{44}$ Similarly, nuclear bomb tests in outer space were "useful" to Van Allen, Iowa's first space scientist and one of the world's first geoengineers.

42. Flansburg, "No Ivory Tower."

43. Saward, Bernard Lovell, 242.

44. Fleming, Fixing the Sky, 225-68. 